\title{
Educação superior sob uma ótica comparada
}

http://dx.doi.org/10.221713/2358-2332.2016.v14.1467 ${ }^{1}$

Robert Evan Verhine, doutor em Educação pela Universität Hamburg, Alemanha, professor titular aposentado da Universidade Federal da Bahia (Ufba), Salvador, BA, Brasil. E-mail: verhine@gmail.com.br.

A importância, para os tempos atuais, do campo de estudos reconhecido como Educação Comparada é inegável. Sua relevância para os que se envolvem na pesquisa, na política e na prática educacional é evidenciada por suas três dimensões estruturantes. A primeira, de natureza científica, busca construir teoria sobre as interfaces existentes; a segunda, de cunho pragmático, tenta identificar lições de iniciativas educacionais desenvolvidas em outros países para a melhoria de políticas e práticas locais; e a terceira, de foco internacional, leva à compreensão de outras culturas e nações para promover intercâmbios e paz no âmbito internacional. A Educação Comparada, como área específica de estudo, começou a se consolidar internacionalmente a partir da década de 1950, com o desenvolvimento de suas próprias teorias, metodologias, sociedades acadêmicas, periódicos e programas de pósgraduação. No Brasil, a Educação Comparada foi promovida por meio da publicação de obras importantes, da realização de eventos de cunho internacional e da inclusão de disciplinas sobre o assunto no currículo de programas de pedagogia de nível superior. Mas a área perdeu espaço na década de 1980 no Brasil, vítima de uma tendência da época de desconfiar de ideias e inovações oriundas do exterior. No entanto, mais recentemente, diante da predominância dos processos associados à globalização, o campo vem, paulatinamente, sendo ressuscitado. Porém, os avanços na área têm sido limitados pela falta de literatura em português, necessária para estimular e fundamentar estudos comparados e para sensibilizar e ensinar alunos de graduação e de pós-graduação a respeito da referida área de conhecimento. É neste contexto que se percebe o valor do livro Expansão das universidades em uma economia global em mudança: um triunfo dos BRIC?, cuja tradução do inglês para o português, bem como a divulgação no âmbito brasileiro foram recentemente promovidas pela Capes ${ }^{2}$.

O livro enfoca, de forma comparativa, o desenvolvimento da educação superior nos quatro países BRIC (Brasil, Rússia, Índia e China) e analisa as similaridades e diferenças que eles mantêm entre si ao enfrentar os desafios da globalização via investimentos na expansão e na melhoria de seus sistemas de educação superior. A obra

\footnotetext{
${ }^{1}$ Como citar: ABNT NBR 6023:2002 e incluir o DOI.

${ }^{2}$ CARNOY, M. et al. Expansão das universidades em uma economia global em mudança: um triunfo dos BRIC? Brasília, DF: Capes, 2016, 435 p. (Tradução de: UNIVERSITY EXPANSION IN A CHANGING GLOBAL ECONOMIC: TRIUMPH OF THE BRICS?, originalmente publicado em inglês pela Stanford University Press, Stanford, CA, EUA, 2013.)
} 
é de natureza unificada e colaborativa, envolvendo oito autores representando os países em questão. Todos liderados por Martin Carnoy, da Universidade de Stanford, reconhecido internacionalmente por seus estudos no campo da Economia da Educação. É importante destacar que o livro não é uma coletânea sobre cada país, mas um trabalho coeso, integrado e organizado por temas que confrontam a situação de cada um deles com os demais integrantes do grupo. Além da expansão do ensino terciário, outros temas relacionados com a educação superior são aprofundados, tais como financiamento, estrutura e organização; grau de equidade; nível de qualidade e ligação com o mercado de trabalho. Ademais, vários tópicos complementares são abordados, como: caraterísticas curriculares, mecanismos de admissão estudantil, políticas de ação afirmativa, processos de mudança institucional e esforços para promover internacionalização da instituição. A visão predominante dos autores é própria da Economia, por isso informações sobre cursos, taxas de retorno e demandas de empregadores são priorizadas. Nesta mesma ótica, as áreas de Engenharia e Computação recebem atenção especial, com base na sua suposta relevância para desenvolvimento econômico. Vale ressaltar que fatores históricos, políticos e culturais são também considerados ao contextualizar as tendências e decisões observadas. Abrangendo mais de 400 páginas, a obra fornece uma grande quantidade de dados estatísticos, em muitos casos, produtos de análises originais usando bancos de dados pouco explorados. Tais dados são apresentados por meio de 60 tabelas e figuras e, em conjunto com outras informações de natureza qualitativa, são analisados e discutidos no âmbito de um texto redigido de forma clara e didática.

O argumento central do livro diz respeito às altas taxas de retorno para a educação superior, ao crescimento marcante do número de alunos concluintes do ensino secundário e à necessidade de competir efetivamente no mundo globalizado. Estes pontos têm gerado pressões nos países BRIC para expandir rapidamente o acesso a suas instituições de ensino terciário. Os quatro países têm enfrentado o desafio com relativo êxito, todavia de forma diferenciada e, em todos os casos, com repercussões nem sempre positivas. Diferentemente da expansão que ocorreu na Europa e na América do Norte no século passado, a ampliação da educação superior nos países integrantes do BRIC não tem sido mediante um ensino fortemente subsidiado por governos abastados por impostos, mas sim pelo repasse de um montante significativo dos custos para os usuários, ou seja, os estudantes e suas famílias.

$\mathrm{Na}$ visão dos autores, esta estratégia é compreensível ao considerar as atuais limitações na disponibilidade de recursos públicos, a necessidade urgente de resolver problemas de oferta e o fato de que a educação superior gera para seus concluintes altas taxas de retorno privado. Embora a estratégia geral tenha sido comum, os mecanismos utilizados para o repasse dos custos se diferenciam de um país para outro, o que sugere a influência de ambientes históricos e políticos de cunho nacional na busca para solucionar problemas compartilhados. Rússia e China têm focado na expansão de seus sistemas públicos, porém eles cobram mensalidades substanciais dos alunos que ingressam. Índia e Brasil, por outro lado, têm preservado a relativa gratuidade de suas universidades públicas, mas limitando o acesso para poucos, ao mesmo tempo que têm promovido forte expansão do setor privado. 
Assim, em todos os quatro países, grande parte dos alunos de educação superior precisa pagar por seus estudos. Além disso, a expansão promovida pelos países do BRIC tem ocorrido por intermédio da criação de sistemas duais, nos quais existem universidades elitizadas, com seleção exigente e focada na pesquisa, ao lado de instituições de massa, tipicamente de baixa qualidade. De acordo com a análise dos autores, nos quatro países, o diferencial de qualidade entre os dois tipos de instituição (elitizadas e não elitizadas) tem aumentado no decorrer do tempo. Sendo que as instituições elitizadas atendem de forma predominante alunos de origem favorável e as instituições de massa admitem, principalmente, alunos de origens mais humildes, a expansão tem sido acompanhada por uma segmentação cada vez mais nítida entre setores populacionais mais e menos favorecidos. Esforços para contornar esta tendência mediante, por exemplo, ações afirmativas têm ajudado a atenuar a situação, mas tendências fortes de inequidade permanecem. Considerando que geralmente as universidades de elite são públicas e têm altos níveis de gasto por aluno, e que os melhores alunos, em sua maioria, vêm de classes sociais mais elevadas, nos quatro países em questão, a maioria dos subsídios governamentais, para o ensino superior, acaba indo para as famílias mais ricas da nação.

O livro revela que a educação superior no Brasil é diferente dos outros componentes do BRIC em vários sentidos. O Brasil possui o setor privado mais forte, é o único que oferece ensino público totalmente gratuito e só ele possui universidades de natureza religiosa. $\mathrm{O}$ Brasil produz o menor número de engenheiros per capita $\mathrm{e}$, como a Índia, oferece uma educação básica de qualidade muito baixa. Por outro lado, apenas o Brasil e a Índia adotam políticas de ação afirmativa e, comparativamente, o Brasil é o país que desenvolve o sistema de avaliação de educação superior mais aprimorado, embora os autores do livro questionem a eficácia da divulgação dos resultados de provas como instrumento para promover qualidade. Do ponto de vista comparativo, observa-se que enquanto Rússia e China estão priorizando a criação de um número pequeno de world-class universities que se situam no topo dos rankings internacionais, o Brasil e a Índia adotam posturas mais democráticas, tentando assegurar uma qualidade mínima que se aplica a todas as suas instituições. No caso da Índia, o prestígio de suas universidades é garantido por meio da seletividade de seus alunos. No Brasil, as instituições que se destacam são caracterizadas por programas de pós-graduação de alta qualidade, o que permite a efetiva participação do país na comunidade acadêmica internacional.

Segundo o livro, todos os quatro países adotam estratégias que são racionais e coerentes em termos do contexto histórico e cultural de cada um. Embora seja defensável, a política de educação superior adotada pelo Brasil talvez não seja ideal. O livro revela que, no setor privado, a busca para maximizar retornos financeiros (ou lucros, no caso de $40 \%$ das instituições brasileiras) prejudica a qualidade do ensino, pois instituições são incentivadas a aumentar a relação de aluno por professor, abaixar o salário docente e minimizar investimentos em infraestrutura. E há indícios de que a referida qualidade de instituições privadas se encontra em declínio, pois o gasto por aluno em tais estabelecimentos é cada vez menor. Por outro lado, pode-se argumentar que os incentivos, que minam a qualidade, não prevalecem nas instituições públicas, logo, seria melhor expandir o ensino público com cobrança de mensalidades do que fortalecer o 
setor privado. Nos dois casos, a maioria dos alunos pagaria, mas no caso que prioriza a expansão do setor público a garantia de qualidade fica mais fortemente assegurada.

Um dos postulados principais do livro trata da centralidade do Estado na determinação das políticas de educação superior. Ao analisar comparativamente os quatro países em pauta, os autores enfatizam que o Estado brasileiro é relativamente fraco, promovendo educação superior de forma indireta, conforme indicado pela ênfase dada ao setor privado. Ao desenvolver este argumento, a análise não considera adequadamente duas tendências recentes. Uma diz respeito ao investimento maciço do Estado brasileiro nas instituições federais (universidades e institutos tecnológicos), a partir de 2007, no âmbito do Reuni ${ }^{3}$. Desde então, as matrículas têm crescido mais rapidamente no setor público do que no setor privado, tendência contrária à perspectiva repassada pelos autores sobre o Brasil que visa um setor público contido e um setor privado em dinâmica expansão. A segunda tendência não considerada é a relevância do Fies para a sustentação das instituições privadas de educação superior. Segundo os autores, as instituições privadas são totalmente financiadas pelos alunos e suas famílias. Porém, com programas como $\mathrm{Fies}^{4}$ e Prouni ${ }^{5}$, é o setor público que garante a sobrevivência (e os lucros) de muitos estabelecimentos que compõem o setor privado. Desta forma, o Estado brasileiro faz um papel muito mais central do que o retratado no livro. De fato, comparado com os outros países BRIC, o governo brasileiro é o que assume maior peso em relação ao financiamento da educação superior, pois custeia um setor federal em expansão que é gratuito para seus usuários, ao mesmo tempo em que aloca uma quantidade significativa de recursos públicos nas instituições privadas do país. Com certeza, para muitos, este compromisso governamental em relação à educação superior é visto como algo muito positivo. Mas uma leitura do livro em questão sugere uma perspectiva mais negativa, pois um dos temas mais enfatizados no decorrer do texto é a importância da qualidade da educação básica para a qualidade e equidade da educação superior. Se a educação básica no Brasil é fraca (conforme evidenciado no livro), conclui-se que a política educacional recentemente adotada pelo governo brasileiro não seja a mais apropriada.

Além das omissões anteriormente mencionadas, o livro sofre algumas outras limitações que merecem menção. Os autores afirmam que sua perspectiva é "única" por focar o papel do Estado no desenvolvimento da educação superior, porém tal perspectiva é a que predomina na literatura brasileira sobre o assunto. Também é questionável o fato de que os autores adotam uma posição relativamente determinística ao explicar a influência do contexto histórico na adoção de políticas de educação superior. Seria interessante, por exemplo, se os autores tivessem discutido casos em que as decisões fossem resultados de uma dinâmica de interações entres atores de diferentes orientações políticas e sociais. Como indicador do sucesso das ações tomadas, os autores citam o fato de que os estudantes universitários nos quatro países estão "satisfeitos" com sua educação, mas tal satisfação é difícil de medir e não necessariamente indica que "[...] a

\footnotetext{
${ }^{3}$ Reuni - Programa Reestruturação e Expansão das Universidades Federais.

${ }^{4}$ Fies - Programa de Financiamento Estudantil.

${ }^{5}$ Prouni - Programa Universidade para Todos. 
expansão tem sido bem-sucedida do ponto de vista da legitimação do Estado", como afirmam os autores na página 251. Outro elemento de difícil mensuração é a distinção, repetidamente feita no livro, entre universidades de elite e universidades de massa. Embora não explicitado claramente, ao que parece no caso brasileiro, as universidades de elite são as públicas (federais e estaduais) e algumas universidades de natureza religiosa, enquanto o resto das instituições de educação superior é considerado do tipo massificado. Esta diferenciação é muito duvidosa, pois coloca, por exemplo, as universidades públicas das regiões mais ricas do país no mesmo patamar das instituições públicas mais pobres, algo não sustentado pelos dados avaliativos atualmente disponíveis. Além disso, existe no livro certa confusão sobre o uso da palavra "universidade", como aparece no título. No caso brasileiro, fica evidente que são as instituições de educação superior, e não apenas as universidades, que são focadas na análise. Mas não fica claro se a mesma situação se aplica aos outros três países também. Os termos "universidade", "faculdade", "ensino pós-secundário" e "ensino terciário" são utilizados no texto o que dificulta ao leitor compreender se as nomenclaturas são sinônimas ou não. Na verdade, é fato que o significado desses termos varia de um país para outro, mas esta possibilidade não é tratada pelos autores.

Outra aparente limitação do livro é também uma virtude. Os autores nunca respondem a pergunta colocada em seu título. A expansão das universidades nos países componentes do BRIC representa um triunfo? Considerando a complexidade do assunto e a sofisticação da análise, não fica surpreendente a ausência de uma resposta, pois, em todos os países, os avanços foram acompanhados por problemas e desapontamentos. Mas fica evidente que os autores tendem a ver o cenário positivamente. Será que todos os leitores teriam o mesmo ponto de vista? Provavelmente não, especialmente no momento atual, pois o sucesso econômico que marcou a emergência dos países em questão tem evaporado nos tempos recentes.

As limitações citadas acima são pequenas ao considerar as grandes contribuições do empreendimento. Como um todo, o livro é único no contexto brasileiro que fornece informações detalhadas sobre o Brasil e três outros países importantes, oferecendo comparações que provocam reflexões avaliativas sobre políticas de educação superior.

O livro ilustra de forma coerente e articulada o valor de análises de cunho internacional e o uso da metodologia da Educação Comparada. Uma obra que alunos, professores e formuladores de política, atuantes nos campos da Educação, da Política, da Economia e das Relações Internacionais, vão achar profundamente instigante e extremamente útil. 